\title{
Adduct Formation and Context Factors in Drug Hypersensitivity: Insight from Proteomic Studies
}

\author{
Juan M. González-Morena ${ }^{\mathrm{a}}$, María I. Montañez ${ }^{\mathrm{b}}$, Giancarlo Aldini ${ }^{\mathrm{c}}$, Francisco J. \\ Sánchez-Gómez ${ }^{\text {a }}$, Dolores Pérez-Sala ${ }^{a} *$ \\ ${ }^{a}$ Department of Chemical and Physical Biology. Centro de Investigaciones Biológicas, C.S.I.C., Madrid, \\ Spain. ${ }^{b}$ Research Laboratory, IBIMA-Regional University Hospital of Málaga-UMA, and BIONAND- \\ Andalusian Centre for Nanomedicine and Biotechnology, Málaga, Spain. ${ }^{c}$ Department of Pharmaceutical \\ Siences. Università degli Studi di Milano, Milan, Italy.
}

Running title: Proteomics in drug hypersensitivity

\begin{abstract}
Drug hypersensitivity reactions result from the activation of the immune system by drugs or their metabolites. The clinical presentations of drug hypersensitivity can range from relatively mild local manifestations to severe systemic syndromes that can be life-threatening. As in other allergic reactions, the causes are multifactorial as genetic, metabolic and concomitant factors may influence the occurrence of drug hypersensitivity. Formation of drug protein adducts is considered a key step in drug adverse reactions, and in particular in the immunological recognition in drug hypersensitivity reactions. Nevertheless, non-covalent interactions of drugs with receptors in immune cells or with MHC clefts and/or exposed peptides can also play an important role. In recent years, development of proteomic approaches has allowed the identification and characterization of the protein targets for modification by drugs in vivo and in vitro, the nature of peptides exposed on MHC molecules, the changes in protein levels induced by drug treatment, and the concomitant modifications induced by danger signals, thus providing insight into context factors. Nevertheless, given the complexity and multifactorial nature of drug hypersensitivity reactions, understanding the underlying mechanisms also requires the integration of knowledge from genomic, metabolomic and clinical studies.
\end{abstract}

Keywords: drug allergy, protein haptenation, amoxicillin, proteomics, oxidative stress

*Address correspondence to this author at the Department of Chemical and Physical Biology Centro de Investigaciones Biológicas, C.S.I.C., Ramiro de Maeztu, 9, 28040 Madrid, Spain, Phone: 34918373112, FAX: 34915360432, Email: dperezsala@cib.csic.es

\section{INTRODUCTION}

Drug-induced activation of the immune system leads to hypersensitivity reactions that compromise therapeutic opportunities and may entail great severity, threatening the life of the patient or resulting in life-lasting sequelae. The clinical entities arising from drug hypersensitivity can be very varied. The presentations can range from contact dermatitis, urticaria, and angioedema, to severe anaphylaxis or the toxic epidermal necrolysis occurring in the Stevens-Johnson syndrome, among others.

Many factors contribute to the ability of drugs to induce hypersensitivity reactions. Besides drug reactivity, genetic factors from the patient, factors affecting drug absorption and metabolism, as well as concomitant factors need to be taken into account.

From a general perspective, it is necessary that several elements concur for activation of the immune system: an antigen that is processed and presented by antigen presenting cells (APC) to T-cells via MHC 
molecules, a T cell repertoire able to recognize this antigen and co-stimulatory signals or a regulatory response [1]. The interactions of drugs with proteins are critical for the induction of hypersensitivity responses. There is still controversy regarding the need of covalent protein modification by drugs or their metabolites (haptenation), the minimum size of immunogenic structures or the requirement of a carrier for small molecules in order to activate the immune system. Nonetheless, protein-drug adduct formation is considered an important factor in hypersensitivity reactions in many cases. Haptenation can have consequences similar to that of protein modification by endogenous electrophiles [2]. It can induce severe alterations of protein structure and/or function, including protein unfolding, cross-linking and formation of aggregates. These alterations can affect cellular functions and compromise the capacity of cells to degrade damaged proteins leading to cytotoxicity and generation of danger signals or damage associated molecular patterns (DAMPS) [3]. An important consequence of protein modification may be also the generation of an unfolded protein response, which can have deleterious consequences for cells. These effects can contribute to the coactivation of the immune system.

In addition, protein modification can result in increased immunogenicity, since modified proteins can be recognized as "non-self” proteins or neoantigens. In certain autoimmune diseases, proteins suffer posttranslational modifications that render them immunogenic. For instance, citrullinated peptides from several endogenous proteins, including extracellular and intracellular proteins like vimentin, alphaenolase and histones, act as antigens to which auto-antibodies are detected in several inflammatory diseases, like arthritis [4, 5]. Moreover, carbamylated and acetylated vimentin are also recognized by autoantibodies from patients [6]. Indeed, it has been shown that some of these modified peptides can bind certain HLA alleles [7, 8]. Therefore, the possibility exists that drug-protein or peptide adducts can act as neoepitopes.

Insight into the mechanisms of drug hypersensitivity in order to achieve a better prevention, diagnosis and treatment requires multidisciplinary approaches. Proteomic techniques can provide information on the drug-adducts formed, which in some cases may be critical for activation of the immune system.

Moreover, identification of adducts formed in vitro or in patients' sera can provide novel antigenic determinants for diagnosis, and, in the mid-term perhaps for desensitization strategies. In many cases, in vitro tests for diagnosis are necessary due to the risk of performing provocation tests. In vitro tests employ complexes of the drugs of interest with serum albumin or with electrophilic amino acids, synthetic polymers or nanostructures to probe the antibodies present in the patients' sera or to perform cellular activation assays $[9,10]$. Nevertheless, these structures may not represent the endogenous antigens and result in false negatives or low sensitivity. Identification of the "actual" adducts formed in patients allows using more relevant antigens for in vitro tests and may also provide information on the processes underlying cross-reactivity or selectivity of drug hypersensitivity, which, in some cases relate to the structure of the drug.

In recent years, development of proteomic and mass spectrometry (MS) techniques is yielding a great wealth of information on protein adduction by endogenous and exogenous reactive compounds. Identification of covalent drug-protein adducts can use label-dependent and label-free techniques. In the first case, the drug is labeled with a fluorescent or a biotin moiety [11]. These approaches enable detection of adducts by the appropriate techniques generally after one-dimensional (1D) or twodimensional (2D) electrophoresis and direct detection in the gel or after transfer to a membrane (blot) (Fig. 1). Whereas these techniques are useful to visualize adducts and to identify the modified proteins, for instance by peptide mass fingerprinting, they usually do not provide information on the site of modification and/or structure of the adducts. Other labeling strategies include "click technology" that uses azido and alkenyl derivatives of electrophilic compounds for subsequent adduct derivatization and detection $[12,13]$, or synthesis of isotopically labeled derivatives recognizable by MS. In cellular and in vitro model systems, drugs or their metabolites can be labeled to facilitate the detection, enrichment and/or identification of adducts. However, these techniques cannot be used to study adduct formation in patients. 
The development of MS strategies of high resolution and sensitivity allows addressing the study of adduct formation in patients, which necessarily has to be performed by means of label-free approaches. In the label-free techniques, protein adducts can be detected by specific antibodies against the drug moiety when available, or by MS, identifying the mass increment corresponding to the adduct or to the specific ions resulting from its fragmentation in the spectrometer under the different dissociation conditions (diagnostic fragments). Moreover, MS/MS techniques can provide information on the precise residues that are modified on proteins and on the structure of the modifying moieties. In addition, when possible, derivatization of the adduct can provide additional means of detection. Highly specialized equipment and protocols are required for the detailed structural characterization of adducts by high resolution MS, whereas the requirements for adduct detection by immunological or label-dependent approaches can be met by most biochemistry laboratories.

It is important to consider that knowledge of drug metabolism may be critical for identification of drugprotein adducts since, often is not the parent drug but its metabolites the ones responsible for protein modification and toxicity. Acetaminophen (paracetamol), metamizol, nevirapine, and celecoxib, among others, are examples of this [14]. Therefore, it is key to have a good knowledge of metabolic transformations that can lead to chemically reactive drug metabolites. To achieve this knowledge is necessary to develop analytical strategies to identify these metabolites and their potential [15]. Thus, proteomic studies on drug hypersensitivity are strongly dependent on advances on drug metabolomics.

Besides drug metabolism, the cellular capacity for exporting drugs or drug conjugates will influence their accumulation. These processes depend also on genetic factors from the patient. In this sense, individual susceptibility can be correlated with genomic studies, and in fact, associations of genetic variants with the risk of developing drug hypersensitivity have been found for many drugs [16-18].

In addition, access to the synthetic or purified drug metabolites and in vitro generation of the drug- or metabolite-protein adduct can provide valuable information about the immunogenic structures since, in some cases the adducts formed are not stable and can suffer transformations difficult to predict, giving rise to structures that may be responsible for the hypersensitivity reaction. Therefore, the contributions of chemical synthesis and analytical chemistry to this field are critical.

On the other hand, quantitative proteomics, as in the liquid chromatography-MS-based approaches SILAC (stable isotope labeling amino acids in cell culture) and iTRAQ (isobaric tags for relative and absolute quantitation) provides information on the changes in protein levels that may occur upon exposure to a drug in a tissue or in a cellular experimental system. In addition, 2D-electrophoresis-based methodologies, like DIGE (differential in-gel electrophoresis), can be used with quantitative purposes $[19,20]$. The proteomic characterization of tissues can yield information to unveil or confirm pathogenic mechanisms. For instance, proteomic characterization of serum and blister liquid in drug-induced toxic epidermal necrolysis supported the involvement of macrophages and keratinocytes in the pathogenesis of this reaction [21]. In this regard, as for many diseases, proteomics can also be useful in the identification of biomarkers for predisposition to drug or chemical hypersensitivity [22]. Proteomic studies on identification of potential biomarkers have been carried out in animal models, i.e., in mice subjected to hapten challenge [23], and in patients suffering from various types of adverse drug reactions [24]. The importance of proteomics in several aspects of drug toxicity has been the subject of a comprehensive review covering the characterization of the proteome and adductome [25].

In addition, proteomic studies can provide valuable information on the context factors contributing to hypersensitivity reactions. Among these, the metabolic and redox state of cells are important factors that can influence the extent of the formation of drug-protein adducts, as well as their nature [26], as it will be detailed below. Therefore, redox proteomics and proteomics of electrophilic modifications combined with studies on drug exposure may provide valuable information for the understanding of the haptenation process and its involvement in drug hypersensitivity. 
Nevertheless, in spite of extraordinary advances in the knowledge of the interactions of drugs or their metabolites with proteins in recent years, the challenge remains to understand, and therefore predict, when the formation of such complexes, which also occur in healthy subjects, is going to trigger an allergic reaction. For this, a thorough understanding of the concurrent individual circumstances is necessary. In summary, multiple disciplines should contribute to untangle the complex mechanisms for drug hypersensitivity which are subject to individual and context factors as well as to factors depending on each drug. In this article, we discuss general aspects of drug hypersensitivity, paying special attention to findings obtained through proteomic approaches on both drug-protein interactions and on context factors such as redox status and inflammation. However, given the high number of excellent works in this topic, some of them may not be reflected in the present review.

\section{PROTEOMICS IN THE CHARACTERIZATION OF CONTEXT FACTORS FOR DRUG HYPERSENSITIVITY REACTIONS}

\subsection{Redox proteomics}

Situations associated with oxidative stress are known to act as cofactors for allergic reactions of diverse nature in the clinic. Moreover, the relationship between oxidative stress and adduct formation, as well as its importance in the generation of danger signals are known. However, the precise connections have not been elucidated.

Redox status is determined by the action of low molecular weight agents and macromolecules. Glutathione (GSH) is the most important low molecular weight thiol determining the redox status of cells. GSH can modulate the redox balance by acting as a reduction equivalent in cells and prevent the oxidation of proteins' sulfhydryl groups. Additionally, GSH is involved in the detoxification of xenobiotics through its conjugation that can be catalyzed by detoxifying enzymes such as GSTP1-1, or occur non-enzymatically [25, 27]. GSH-drug conjugates are finally detoxified through their export by MDR transporters that can be themselves sensitive to redox or electrophilic modifications [28].

Among the macromolecules involved in the control of redox status are enzymes that regulate the levels of GSH, like $\gamma$-glutamyl-cysteine synthase, the balance between other redox-active cofactors, like $\mathrm{NAD}(\mathrm{P}) / \mathrm{NAD}(\mathrm{P}) \mathrm{H}$ or the oxidative state of the cellular proteins. Enzymes such as aldose reductase (AKR1B1), GSTP1-1 and thioredoxin can modulate the cellular redox state. These redox-regulating proteins have been implicated in the modulation of certain hypersensitivity reactions, such as asthma [29, 30]. Proteomics has rendered critical information on the regulation of cellular redox status and on protein modifications [31]. Among these modifications the various forms of cysteine oxidation can play regulatory roles and impact in drug metabolism and disposition. Conversely, certain drugs can regulate the expression of redox-regulating proteins, which in turn, can be modified by drug addition, with consequences on the redox status. Therefore, a complex regulation exists between redox regulation and drug adduction.

Interestingly, adduct formation by sulfamethoxazole in antigen presenting cells has been shown to increase under conditions of oxidative stress [32]. Indirect evidence based on the use of the sulfenic acid probe dimedone, indicates that this effect may be due, at least part, to the improvement of binding of the drug to oxidized proteins, particularly to cysteines oxidized to sulfenic acid [32].

In plasma, glutathione levels are very low and the main free thiol-containing molecule is albumin, which is the main antioxidant and plays an important role in plasma redox status. Albumin possesses 35 cysteine residues, all of which, except Cys34 are involved in the formation of structural disulfide bonds. Cys34 is responsible for the antioxidant action of albumin and can scavenge several electrophilic and oxidant compounds $[33,34]$. Moreover, the free thiol content of albumin is reduced in pathophysiological conditions associated with oxidative stress, such as chronic renal failure, coronary heart disease, or during exercise. Several oxidation forms of Cys34 have been identified, including mixed disulfides and irreversible oxidations like sulfonic acid [34]. Interestingly, Cys34 is also the target for covalent 
modification by various drugs involved in hypersensitivity reactions, including abacavir, nevirapine, and gold antiathritic agents [35-37]. Therefore, the redox status will affect the availability of Cys34 for modification by these drugs.

\subsection{Interactions with inflammation}

It is obvious that drug hypersensitivity reactions, except when elicited by provocation tests, occur in the context of therapeutic regimes, therefore coincident with some pathological condition. Very often the diseases treated involve some kind of metabolic alteration, inflammation and/or infection. Therefore, the risk for concomitant factors and generation of danger signals is increased. Proteomic techniques can play an important role in the characterization of the context factors that may contribute to the hypersensitivity reaction.

Associated pathogenic conditions such as infection or inflammation can have important consequences for drug adduct formation by various mechanisms, including the generation of electrophilic reactive mediators that also target proteins and may compete or cooperate with drug-induced modifications. As reflected in Figure 2, in a situation of inflammation, both drugs and endogenous electrophilic mediators coexist. Modification of proteins by electrophilic compounds can induce protein unfolding, thus exposing novel sites for drug adduction. In addition, as outlined above, in specific cases, formation of drug adducts may be more efficient on oxidized proteins [38]. Certain proteins are particularly prone to modification by endogenous or exogenous electrophiles. That is the case of GSTP1-1, which is the target for modification by cyclopentenone prostaglandins, ethacrynic acid, and chlorambucil [39-41]. Some of these reactive compounds can compete for the same sites on the protein [41]. Therefore, multiple combinations of modified species can potentially rise by the coexistence of drug treatment, oxidative stress and reactive inflammatory mediators. Electrophilic mediators can also act by indirect mechanisms including the regulation of the expression and/or activity of detoxifying enzymes, and affecting the expression or activity of multidrug resistance proteins [28].

System approaches have been used to characterize the modification of proteins by endogenous or exogenous electrophiles and their functional consequences. In some of these studies, endogenous lipid electrophiles, typically generated under inflammatory conditions, have been used as models due to their broad reactivity towards nucleophiles and the availability of detection methods [13, 42].

Also, coexistence of inflammatory conditions may potentiate the toxic effects of drugs or reduce the threshold at which they can induce adverse effects. For instance, acetaminophen has been shown to increase the production of inflammatory cytokines in a macrophage cell line, an effect that is potentiated by bacterial lipopolysaccharide and may be related to an increased bioactivation of acetaminophen by cytochromes and cyclooxygenases [43].

We have recently reviewed the methodology and challenges of proteomic analysis of modifications by various inflammatory mediators, which in many cases may be applicable to drug-protein interactions [ 42 , 44]. Nonetheless, combinations of approaches will be needed to fully characterize the protein modifications generated in pathophysiological conditions under therapeutic regimes.

\section{PROTEOMICS IN THE CHARACTERIZATION OF DRUG-PROTEIN INTERACTIONS}

\subsection{Non-covalent drug-protein interactions}

Although drug hypersensitivity reactions are most often attributed to covalent interactions of drugs with proteins, they can also be due to non-covalent interactions. For instance, interaction of drugs with peptides exposed on MHC can activate the immune system or induce peptide conformations that are more immunogenic, in what is known as "the pharmacological interaction concept" [45]. Quantitative high throughput MS-based approaches have allowed to characterized the endogenous peptides presented by MHC class I molecules, or immunopeptidome [46]. Interestingly, altering cellular metabolism, influences 
the immunopeptidome, which provides a link between metabolic context factors and the immune response [46].

Thus, proteomic approaches can provide information on the nature of peptides exposed by various cell types treated with drugs, and on the quantitative differences between peptides exposed by control and drug-treated cells.

An interesting example of non-covalent interaction is that of abacavir, a nucleoside analog used as inhibitor of viral reverse transcriptase that has been the subject of study of many excellent works in this field. Induction of drug hypersensitivity by abacavir seems to be directly related to the expression of the HLA-B*57:01 type. Proteomic experiments have explored the patterns of peptides associated to HLA$B * 57: 01$ in cellular assays. It was shown that abacavir but not other drugs enhanced the binding of a selfpeptide to HLA-B*57:01. Moreover, the peptides exposed on HLA-B*57:01 were different in control and in abacavir-treated B-cells. Thus, abacavir-induced autoimmunity could be due to alteration in the quantity and/or quality of self-peptide loading into HLA-B*57:01, or related to potential alterations in the peptide binding cleft or in the peptide-loading complex, finally generating a panel of neo-antigen peptides [47]. In addition, it has been reported that abacavir can activate T-cells both through a direct interaction with MHC molecules at the APC surface, and through interaction with intracellular MHC [48], which elicits peptide exposure as a consequence of abacavir treatment.

iTRAQ technology and LC-MS platform approaches have been used to accomplish the identification of MHC class I-associated peptide antigens in cisplatin-resistant ovarian cancer cells, which may be recognized by specific cytotoxic T-lymphocytes [49]. Therefore, from the above examples the possibility emerges that drug hypersensitivity is favored by drug-induced presentation of a different repertoire of peptides or by quantitative differences in the peptides exposed.

In addition, numerous proteins including HSA, GSTP1-1, nuclear and membrane receptors can bind drugs through non-covalent interactions [50,51]. MS approaches exist that allow detection of non-covalent drug protein complexes. In the case of the enzyme aldose reductase, a complex with non-electrophilic prostaglandins that is reversed under denaturing conditions has been observed by MALDI-TOF MS [52]. This type of interaction can affect the function and conformation of the proteins and/or shield specific sites for modification by other drugs or endogenous mediators. For instance, nuclear receptors of the PPAR family are able to accommodate several types of drugs in their binding sites. In fact, many of these drugs can act as agonists for these receptors [53]. However, the presence of drugs at the binding site can hamper activation by endogenous ligands and/or shield reactive residues present in this region from modification by electrophilic compounds [54]. Given the importance of many of these proteins in the inflammatory response, these interactions could alter the response of immune cells. Nevertheless, the direct implication of non-covalent drug-protein complexes, such as those occurring on albumin, in allergic responses to drugs is not established.

\subsection{Drug-protein adduct formation}

The development of MS strategies is being critical for the characterization of drug-protein adducts, the structure of which is difficult to predict, either because is not the drug, but a metabolite, the molecule responsible for protein adduction or because the adduct can suffer additional chemical transformations (see Figure 3 for the structures and some drugs/metabolites and their adducts). In addition, detection and quantitation of drug-protein adducts are important for the of drug toxicity through non-immunological mechanisms [25].

Acetaminophen can be bioactivated by cytochromes P450 2E1 and also P4503A4 and P450 1A2catalyzed oxidations to the electrophilic intermediate N-acetyl-p-benzoquinoneimine (NAPQI). This metabolite can be detoxified by conjugation to GSH; however, when paracetamol doses are very high, it can accumulate, deplete cellular stores of GSH and form adducts with cysteine residues in proteins [55]. These adducts have been extensively studied, because overdose of this drug is the most frequent cause of 
acute liver failure in developed countries. Liver toxicity correlates with the levels of protein adducts formed, and quantitative methods have been developed to assess the extent of adduct formation as an index to confirm diagnosis, predict toxicity and/or establish prognosis during therapeutic regimes or upon intoxication with this drug $[56,57]$. Nevertheless, the mechanisms of liver toxicity by acetaminophen do not depend in principle from immunological mechanisms, but are related to the perturbation of protein function, redox disbalance and intense oxidative stress damage. These processes have been studied in detail in animal models [58]. Nevertheless, subsequently, release of DAMPs and mediators from cell necrosis can trigger an inflammatory reaction, which interestingly, has been proposed to be beneficial because it helps to remove damaged cells and promotes tissue repair [59].

In the case of abacavir, in addition to the non-covalent interactions with HLA-B*57:01 discussed above, covalent adducts with proteins in vitro and in patients have also been detected. In particular, an adduct of abacavir aldehyde with hemoglobin was observed in HIV patients receiving this drug [60]. This prompted studies on the formation of adducts between this compound and other proteins. In particular, several adducts of abacavir and HSA have been detected in patients, which involve Cys34 alone or forming a crosslinking product with Gln33, and an adduct at His146 [35]. These are dependent on the oxidative transformation of abacavir giving rise to a reactive aldehyde. Moreover, several additional adducts have been observed upon incubation of the synthetic $\alpha / \beta$-unsaturated aldehyde with proteins in vitro [35]. Thus, this reactive metabolite of abacavir could be hypothetically involved in eliciting allergic reactions.

These examples illustrate the fact that the structures of the adducts formed upon drug treatment are not obvious. For this reason, assays with single amino acids or model peptides have been carried out and subjected to different analytical procedures to study their characteristic ion patterns. In the case of the chemotherapeutic agent melphalan, its reactivity towards single amino acids has been recently studied [61]. Characterization of adducts with synthetic tryptic peptides from HSA has been critical for the subsequent identification of the modification sites by amoxicillin in ex vivo samples [62]. Other synthetic peptides and proteins containing nucleophilic residues have been used as models to explore the reactivity of drugs. The binding capacity of a nitrosylated form of sulfamethoxazole has been analyzed by in vitro incubations with the synthetic peptide "DS3", observing that this compound reacts mainly with the cysteine residue [63]. The detoxifying protein GSTP1-1, which contains several reactive cysteines, has been frequently used as a model for exploring adduct formation in vitro and in cells [41, 64], although the direct involvement of drug-modified GSTP1-1 in hypersensitivity reactions is not established. In particular, GSTP1-1 has been shown to form adducts with diclofenac and its metabolite 5'hydroxydiclofenac at cys 14 and 47 [65] and with the toxic reactive metabolite of acetaminophen Nacetyl-p-benzoquinoneimine at cys47 [64]. In this last work, a modified iTRAQ method is described to allow a fine quantitative detection of adduct formation that can be correlated with the functional outcome. Moreover, some drugs, like chlorambucil, can induce intermolecular crosslinking of GSTP1-1 monomers, which can be observed by SDS-PAGE [41]. In vitro studies using HSA and GST as models have also served to characterize adducts formed by the bioactivated metabolite of the reverse transcriptase inhibitor nevirapine, previous to the identification of adducts in samples from patients receiving this therapy [36]. Nevertheless, as stated above, formation of adducts may be necessary but not sufficient to trigger an allergic reactions since it occurs also in non-allergic patients.

Interestingly, in the case of triflusal, the active metabolite produced, 2-hydroxy-4-trifluoromethylbenzoic acid (HTB), is able to form adducts with proteins in an irradiation-dependent manner, for which it has been proposed to be involved in the induction of photosensitivity [66]. Single amino acids as well as HSA have been used to study the photoadduct, which in HSA appears to be located at site I. Moreover, the photoadduct can be produced both upon multi-lamp photoreactor and sunlight irradiation. However, it is not currently known whether this particular adduct may be involved in triggering the allergic reactions produced by this drug. Recently, the small protein ubiquitin has been used as a model for the characterization of HTB adducts by MS. A single adduct was observed after sun-light irradiation of mixtures of ubiquitin and HTB. However, addition does not appear to occur at a specific residue but it can affect any of the lysine residues in ubiquitin (Nuin et al., unpublished data). 
Acyl glucuronides are electrophilic drug metabolites that may form glycation adducts with proteins either by direct acylation or by Schiff base formation [67]. Diclofenac acyl glucuronide is highly reactive and can form adducts with HSA both in vitro and in patients. Exhaustive analysis of the reaction of this metabolite with HSA in vitro has allowed the identification of the adducts present in subjects without drug hypersensitivity [68]. This has shown a complex and varied pattern of modification of albumin in the different subjects, involving diverse lysine residues, and highlighted the fact that modification of albumin is not sufficient to induce a hypersensitivity reaction.

A proteomic approach has been used to identify covalent adducts of an active metabolite of raloxifene, an oral selective estrogen modulator, and cytochrome P450 3A4 [69]. Using a reconstituted cytochrome P450 3A4 system for incubation with the reactive metabolite, followed by trypsin digestion and nanoLC/linear ion trap-Fourier transform ion cyclotron resonance (FTICR) MS, an adduct was identified likely involving the nucleophilic hydroxyl group of Tyr75 of cytochrome P450 3A4.

Approaches with model peptides and proteins can later be integrated in cellular assays to explore the immunogenic potential of the modified structures. For instance, a model peptide as well as HSA, were used as acceptors for the human skin sensitizer 2,4-dinitrobenzenesulfonic acid (DNBS) and 2,4dinitrochlorobenzene (DNCB). After demonstrating the chemical modification, cells were exposed to these chemicals and the formation of adducts with intracellular proteins were evidenced by 2D-PAGE and immunological detection with anti-DNP antibodies. Subsequently, chemically-modified cells were used in functional assays of activation of T-lymphocytes [70].

Blood proteins have received a great deal of attention in studies on drug hypersensitivity, and some of the adducts described for HSA appear summarized in Table 1.

Nevertheless, intracellular proteins are also the targets for adduct formation and therefore, could be involved in triggering allergic reactions. However, there are fewer studies exploring nature of the intracellular adducted proteins. In a study by Sanderson et al., binding of nitroso-sulfamethoxazole to the surface of dendritic cells as well as intracellular adducts of both sulfamethoxazole and nitrososulfamethoxazole were detected using immunological detection with an antibody against the drug [71]. More recently, the irreversible binding of nitroso-sulfamethoxazole and sulfametoxasole to APC has been reported and these cells were able to activate nitroso-sulfamethoxazole-specific T-cells. Thus, this work shows that metabolic activation of sulfamethoxazole by APC can generate antigenic determinants recognized by T cells. In addition, myeloperoxidase is identified by MS as one of the potential targets for modification by nitroso-sulfamethoxazole [72]. In a recent study, we have obtained insight into the identity of the cellular targets for modification by beta-lactam antibiotics, which will be discussed below.

\section{PROTEOMICS IN THE ELUCIDATION OF THE MECHANISMS INVOLVED IN HYPERSENSITIVITY TOWARDS BETA-LACTAM ANTIBIOTICS}

Beta-lactam antibiotics are amongst the drugs most frequently inducing hypersensitivity reactions and they have been the subject of extensive study. The reactivity of beta-lactams antibiotics is well known. Generally, a protein nucleophile, most often the amino group of a lysine residue, attacks the beta-lactam ring producing its opening and the formation of an amide bond (Fig. 3). The high tension of the core structure of penicillins, a four member beta-lactam ring fused to the five-member thiazolidine ring, contributes to the readiness of this process [10]. Adducts formed by beta-lactams and amino acids or proteins have been exhaustively characterized. In addition, this property has been exploited for the generation of complexes between penicillins and butylamine or polylysine to be used in diagnostic procedures. Therefore, adducts formed are stable and can be analyzed by various methods, including MS and NMR.

Early studies on the formation of protein adducts by beta-lactam antibiotics employed trypsin or cyanogen bromide digestion of penicillin-modified albumin from patients, followed by HPLC analysis and sequencing by Edman degradation [73], whereas benzylpenicilloyl content was determined in the 
different fractions by enzyme immunoassay. In this study, Lys190, 195, 199 and Ser193 were identified as residues containing adducted benzylpenicilloyl [74]. Since then, the development of proteomic and MS methods has allowed the assessment the haptenation of HSA by various beta-lactams, both in vitro and in the serum of patients, and in different pathophysiological conditions.

Regarding the identification and characterization of adducts of several beta-lactams, Prof. K. Park and coworkers have performed excellent and exhaustive studies on the detection of drug-protein adducts in general and adducts of beta-lactam antibiotics, in particular, both in vitro and in ex vivo samples from patients. Adducts of flucloxacillin and its metabolite 5-hydroxymethyl flucloxacillin were detected in HSA from the serum of patients treated with this drug [75]. This was achieved by several chromatographic steps followed by MS, and revealed Lys190 and Lys212 as the residues more frequently modified. In another study using three different beta-lactams, namely, piperacillin, meropenem, and aztreonam, Lys190 was found to be modified by the three of them [76]. Haptenic structures generated by piperacillin involving Lys190, 452 and 541 constituted functional antigenic determinants for T-cells [77]. Several HSA residues emerge from these studies as the most frequently modified by the various antibiotics studied, in particular lysines 190, 195 and 199; however notable variations exist in the patterns of modification (reviewed in [10]). The reasons for the differences observed upon in vitro modification of HSA probably reside in structural differences between the beta-lactam molecules or the incubation conditions employed. The differences observed in samples from patients likely arise from variations in the therapeutic regimes, including dosage and administration route or from the presence of concomitant treatments or pathological conditions.

The development of immunological tools has also played an important role in the detection of betalactam-protein adducts in vivo or in experimental systems, and in the design of diagnostic procedures. In earlier studies, HSA and transferrin from the serum of ampicillin-treated patients were identified as proteins modified by this antibiotic by 2D-electrophoresis and western blot with an anti-penicilloyl antibody [78]. Mayorga et al., [79] developed a series of monoclonal antibodies against amoxicillin that were directed or reactive towards different parts of the molecule. Among them, antibody AO3.2, recognized the lateral chain, the structure of which differs in the various penicillins, plus part of the nuclear region and antibody AO19.1 recognized the lateral chain plus the open beta-lactam ring of the molecule. These antibodies were effective at detecting amoxicillin-protein adducts in western blot [62]. In addition, a different anti-amoxicillin antibody has been employed in immunohistochemistry studies showing the distribution of the antibiotic in various tissues in rats [80] and its correlation with the presence of penicillin transporters at these sites. An antibody against a rabbit serum albuminflucloxacillin conjugate has also been developed that recognizes flucloxacillin-adducted proteins in liver extracts from flucloxacillin-treated rats [81]. Moreover, there are commercial antibodies against penicillin that can recognize amoxicillin-protein adducts, although with lower sensitivity than benzyl-penicillin adducts [62].

In a recent work, we employed a combination of MS approaches and immunological detection using several monoclonal antibodies to identify novel serum targets for modification by amoxicillin. This allowed detection of several targets, including HSA, transferrin and light and heavy chains of immunoglobulins, some of which were previously unnoticed [62]. In addition, the modification of HSA was addressed by high resolution MS techniques using both top-down and bottom-up approaches. We firstly evaluated the reactivity of amoxicillin towards nucleophilic residues such as histidine, lysine and cysteine, by measuring the covalent adduction of amoxicillin towards synthetic HSA fragment peptides containing Lys199, His146 and Cys34. The relative abundances of the adduct-bearing with respect to the native peptides were found to be different: the Lys199-containing peptide was the most reactive (12\%) followed by the His146-containing peptide (3\%) while Cys34 was modified in a negligible amount. The ability of amoxicillin to form covalent and non-covalent adducts with HSA was then demonstrated by directly infusing the amoxicillin:HSA reaction mixture into the ESI source. The characterization of these adducts has permitted to establish the stoichiometry of reaction as well as to identify the adducted moiety which, on the basis of the MW, was attributed to the amoxicilloyl residue. Identification of the HSA sites 
covalently modified by the amoxicilloyl residue was then carried out by a bottom-up approach using trypsin and trypsin plus chymotrypsin for protein digestion. When purified HSA was incubated with amoxicillin (5 mg/ml), 6 lysine residues were found adducted, namely Lys190, 199, 351, 432, 541 and 545. When amoxicillin was used at a 10-times lower concentration, only Lys190, 199 and 541 were found to be modified, thus suggesting their greater reactivity [62]. Molecular modeling studies were then performed in view to rationalizing the reactivity of the adducted lysine residues. We found that the adducted lysine residues are characterized either by a very low basicity which render them extremely reactive regardless of their accessibility (as in the case of Lys190 and Lys199), or by a significant accessibility which markedly facilitates their approach by amoxicillin (as seen for Lys351, Lys541 and Lys545). In general, molecular modelling studies have suggested that the marked reactivity of the targeted lysine residues is modulated not only by the residue accessibility, but also by the microenvironment around the lysine residue which can enhance the intrinsic reactivity of the lysine residues and contribute to the binding of amoxicillin through a sort of recognition process which can stably constrain amoxicillin in a pose conducive to adduct formation [62].

The next step was to confirm the ability of amoxicillin to form covalent adducts with HSA in ex vivo samples from healthy subjects under oral amoxicillin administration (acute intake of $1 \mathrm{~g}$ every $8 \mathrm{~h}$ for 48 h). To reach this goal, we used an analytical strategy based on targeted and untargeted MS approaches. Lys190 was identified as the only modification site of HSA in the ex vivo samples and the relative amount of the modified residue ranged from 1 to $2 \%(6-12 \mu \mathrm{M})$ at 24 and $48 \mathrm{~h}$ after the oral intake [82]. Again, the fact that the amoxicillin-HSA adduct is detected in healthy subjects illustrates again that adduct formation is a common phenomenon requiring other factors in order to elicit the allergic reaction.

The avidin-biotin system is characterized by its high affinity interaction. Our group has extensively employed this system in the analysis of protein targets for various reactive electrophiles [83, 84]. Recently, we synthesized a biotinylated analog of amoxicillin for its use in in vitro model systems in order to detect amoxicillin targets with high sensitivity [11]. This analog incorporates a biotin moiety coupled to the amino group in the lateral chain of the molecule. Therefore, as expected, this impairs its recognition by monoclonal antibodies directed against the lateral chain. This lack of recognition allows observing the competition between amoxicillin and its biotinylated analog for binding to protein targets, both in vitro and in cells. Using this analog, the panel of serum proteins that can be modified by amoxicillin in vitro has been expanded, including haptoglobin, which could not be detected by immunological procedures [11]. These studies will provide novel candidates to be used in functional assays of activation of T-cells or other components of the immune system involved in the allergic reaction. Nevertheless, it should be taken into account that introduction of a bulky moiety into the molecule of amoxicillin, like the biotin moiety, could result in steric hindrances of its interaction with certain targets, for which is very important to confirm the results obtained with biotinylated amoxicillin in assays using the parent antibiotic.

Most of the attention regarding adduct formation by beta-lactam antibiotics has been directed towards de characterization of serum proteins, mainly HSA, as a carrier protein for these drugs. Nevertheless, other possibilities can be considered. As discussed above, cell surface or intracellular proteins could also play a role in the activation of the immune system. However, studies addressing the identification and characterization of intracellular targets for the formation of drug-protein adducts are scarce. In a previous work we combined immunological techniques with the use of biotinylated amoxicillin to detect intracellular proteins modified by amoxicillin in several cell types showing that the patterns of modified proteins were cell-type-dependent [11]. Studies in cellular systems can also provide information on the fate of the adducts formed and help elucidate whether they are degraded by lysosomal or proteasomal pathways or directed towards specific cellular compartments. In a recent study, we have used a Blymphocyte cell line to detect, identify and follow the fate of intracellular amoxicillin-protein adducts. Remarkably, we have observed that amoxicillin covalently binds to a subset of proteins in cells, in a manner that does not depend on protein abundance [85]. Moreover, amoxicillin-protein adducts can be detected in the conditioned medium from cells, both in soluble form and in a vesicular fraction. A detailed 
analysis of the generation of this extracellular vesicle fraction revealed that intracellularly haptenated proteins can be incorporated into exosomes and secreted in this fraction. We have shown that exosomes carrying haptenated proteins can be taken up by endothelial cells, which are APC [85], although, at present, the direct involvement of these vesicles in immune cell activation in response to drugs has not been demonstrated. We have observed that amoxicillin can also bind to isolated exosomes. Therefore, the possibility exists for amoxicillin and other drugs to haptenate protein components of exosomes already present in the circulation at the time of administration. These results constitute the first report of haptenated proteins in exosomes [85]. Exosomes act as vehicles of biologically active molecules, including small RNA, MHC molecules, tetraspanins, and signaling proteins, even between distant locations in the organism [86]. In the immune system, exosomes have been reported to contribute to Tcell activation, dendritic cell maturation, antigen presentation and modulation of gene expression [87]. Given the importance of these extracellular vesicles in the activation of the immune system, these observations unveil novel possibilities for hapten formation and transport.

\section{CONCLUSIONS}

Development of proteomic approaches and high resolution MS techniques is providing extremely detailed information on the formation of drug-protein adducts with great sensitivity. This constitutes highly valuable information for elucidating the mechanisms of drug allergy. Nevertheless, integration of knowledge from other fields, including genomics and metabolomics, is required to achieve this goal. In addition, although knowledge of protein-drug adducts will be very important, the contribution of context factors and danger signals to the immune response cannot be overlooked, Cross-talk with redox and inflammatory pathways can determine the extent and nature of the adducts or the modified species formed. There are proteins particularly reactive that have been shown to be the target for various drugs, redox and electrophilic modifications. Under multidrug regimes they could potentially be modified by several drugs at the same time. Among these proteins are HSA in the circulation and GSTP1-1 in cells. Indeed, several protein targets could be considered as platforms for modification by drugs and endogenous mediators that could modify different sites or even compete for the same site(s) on the protein. Assessing the modifications of these proteins in experimental systems and in patients is providing valuable information on the nature of drug protein interactions and their involvement in hypersensitivity reactions.

In summary, multidisciplinary approaches are required to address the pathogenesis of drug hypersensitivity reactions, in the same way that treatment of drug allergy and its sometimes life-lasting consequences requires interdisciplinary clinical care.

\section{LIST OF ABBREVIATIONS}

AKR, aldose keto-reductase

APC, antigen presenting cell

GSH, glutathione

GST, glutathione transferase

HSA, human serum albumin

HTB, 2-hydroxy-4-trifluoromethylbenzoic acid

iTRAQ, isobaric tags for relative and absolute quantitation

LC, liquid chromatography

MHC, molecular histocompatibility complex 
MS, mass spectrometry

SILAC, stable isotope labeling amino acids in cell culture

\section{CONFLICT OF INTEREST}

The authors declare that no conflict of interest exists.

\section{ACKNOWLEDGEMENTS}

This work has been supported by grants SAF2012-36519 and SAF2015-68590R from MINECO/FEDER and RETIC RD12/0013/0008 from ISCIII to D.P.-S., and by RETIC RD12/0013/0001 and CP15/00103 from ISCIII, and PI-0699-2011 and PI-0179-2014 from Junta de Andalucía to M.I.M. All authors contributed to writing of the manuscript. J.M.G-M., M.I.M., F.J.S.-G. and D.P.-S. prepared illustrations.

\section{REFERENCES}

[1] Nhim C, Delluc S, Halgand F, et al. Identification and frequency of circulating CD4(+) T lymphocytes specific to Benzylpenicillin in healthy donors. Allergy, 2013; 68: 899-905.

[2] Pérez-Sala D. Electrophilic eicosanoids: signaling and targets. Chem Biol Interact, 2011; 192 : 96-100.

[3] Anders HJ, Schaefer L. Beyond tissue injury-damage-associated molecular patterns, toll-like receptors, and inflammasomes also drive regeneration and fibrosis. J Am Soc Nephrol, 2014; 25: 1387-400.

[4] Sakkas LI, Bogdanos DP, Katsiari C, Platsoucas CD. Anti-citrullinated peptides as autoantigens in rheumatoid arthritis-relevance to treatment. Autoimmun Rev, 2014; 13: 1114-20.

[5] Muller S, Radic M. Citrullinated Autoantigens: From Diagnostic Markers to Pathogenetic Mechanisms. Clin Rev Allergy Immunol, 2015; 49: 232-9.

[6] Juarez M, Bang H, Hammar F, et al. Identification of novel antiacetylated vimentin antibodies in patients with early inflammatory arthritis. Ann Rheum Dis, 2016; 75: 1099-107.

[7] Hill JA, Southwood S, Sette A, Jevnikar AM, Bell DA, Cairns E. Cutting edge: the conversion of arginine to citrulline allows for a high-affinity peptide interaction with the rheumatoid arthritis-associated HLA-DRB1*0401 MHC class II molecule. J Immunol, 2003; 171: 538-41.

[8] Roark CL, Anderson KM, Aubrey MT, Rosloniec EF, Freed BM. Arthritogenic peptide binding to DRB1*01 alleles correlates with susceptibility to rheumatoid arthritis. J Autoimmun, 2016.

[9] Montanez MI, Najera F, Mayorga C, et al. Recognition of multiepitope dendrimeric antigens by human immunoglobulin E. Nanomedicine, 2015; 11: 579-88.

[10] Ariza A, Mayorga C, Fernández TD, et al. Hypersensitivity reactions to Betalactams: Relevance of the hapten-protein conjugates. J Investig Allergol Clin Immunol, 2015.

[11] Ariza A, Collado D, Vida Y, et al. Study of protein haptenation by amoxicillin through the use of a biotinylated antibiotic. PLoS ONE, 2014; In press.

[12] Vila A, Tallman KA, Jacobs AT, Liebler DC, Porter NA, Marnett LJ. Identification of protein targets of 4-hydroxynonenal using click chemistry for ex vivo biotinylation of azido and alkynyl derivatives. Chem Res Toxicol, 2008; 21: 432-44.

[13] Jacobs AT, Marnett LJ. Systems analysis of protein modification and cellular responses induced by electrophile stress. Acc Chem Res, 2010; 43: 673-83.

[14] Andreu I, Mayorga C, Miranda MA. Metabolomics in Drug Intolerance. Current Drug Metabolism, 2009; 10: 947-955.

[15] Wen B, Fitch WL. Analytical strategies for the screening and evaluation of chemically reactive drug metabolites. Expert Opin Drug Metab Toxicol, 2009; 5: 39-55.

[16] Michels AW, Ostrov DA. New approaches for predicting T cell-mediated drug reactions: A role for inducible and potentially preventable autoimmunity. J Allergy Clin Immunol, 2015; 136: 252-7.

[17] Pirmohamed M, Ostrov DA, Park BK. New genetic findings lead the way to a better understanding of fundamental mechanisms of drug hypersensitivity. J Allergy Clin Immunol, 2015; 136: 236-44.

[18] Agundez JA, Martinez C, Pérez-Sala D, Carballo M, Torres MJ, Garcia-Martin E. Pharmacogenomics in aspirin intolerance. Curr. Drug Metab., 2009; 10: 998-1008. 
[19] Reynolds JL, Mahajan SD, Sykes DE, Schwartz SA, Nair MP. Proteomic analyses of methamphetamine (METH)-induced differential protein expression by immature dendritic cells (IDC). Biochim Biophys Acta, 2007; 1774: 433-42.

[20] Ariza A, Montañez MI, Pérez-Sala D. Proteomics in immunological reactions to drugs. Curr Opin Allergy Clin Immunol, 2011; 11: 305-312.

[21] Paquet P, Meuwis MA, Mazzucchelli G, Delvenne P, Pierard GE. Proteomic kinetic analysis of blister fluid and serum in a patient with drug-induced toxic epidermal necrolysis. A comparison with skin immunohistochemistry. Curr Drug Saf, 2012; 7: 339-51.

[22] Huang P, Ren X, Huang Z, et al. Serum proteomic analysis reveals potential serum biomarkers for occupational medicamentosa-like dermatitis caused by trichloroethylene. Toxicol Lett, 2014; 229: $101-10$

[23] Houtman R, Krijgsveld J, Kool M, et al. Lung proteome alterations in a mouse model for nonallergic asthma. Proteomics, 2003; 3: 2008-18.

[24] Bell LN, Vuppalanchi R, Watkins PB, et al. Serum proteomic profiling in patients with druginduced liver injury. Aliment Pharmacol Ther, 2012; 35: 600-12.

[25] Merrick BA. The plasma proteome, adductome and idiosyncratic toxicity in toxicoproteomics research. Brief Funct Genomic Proteomic, 2008; 7: 35-49.

[26] Oeste CL, Pérez-Sala D. Modification of cysteine residues by cyclopentenone prostaglandins: interplay with redox regulation of protein function. Mass Spectrom Rev, 2014; 33: 110-125.

[27] Suzuki M, Mori M, Niwa T, et al. Chemical implications for antitumor and antiviral prostaglandins: reaction of $\mathrm{D}^{7}$-prostaglandin $\mathrm{A}_{1}$ and prostaglandin $\mathrm{A}_{1}$ methyl esters with thiols. J. Am. Chem. Soc., 1997; 119: 2376-2385.

[28] Díez-Dacal B, Pérez-Sala D. A-class prostaglandins: early findings and new perspectives for overcoming tumor chemoresistance. Cancer Lett, 2012; 320: 150-157.

[29] Yamada Y, Nakamura H, Adachi T, et al. Elevated serum levels of thioredoxin in patients with acute exacerbation of asthma. Immunol Lett, 2003; 86: 199-205.

[30] Ito W, Kobayashi N, Takeda M, et al. Thioredoxin in allergic inflammation. Int Arch Allergy Immunol, 2011; 155 Suppl 1: 142-6.

[31] Lennicke C, Rahn J, Heimer N, Lichtenfels R, Wessjohann LA, Seliger B. Redox proteomics: Methods for the identification and enrichment of redox-modified proteins and their applications. Proteomics, 2016; 16: 197-213.

[32] Lavergne SN, Wang H, Callan HE, Park BK, Naisbitt DJ. "Danger" conditions increase sulfamethoxazole-protein adduct formation in human antigen-presenting cells. J Pharmacol Exp Ther, 2009; 331: 372-81.

[33] Roche M, Rondeau P, Singh NR, Tarnus E, Bourdon E. The antioxidant properties of serum albumin. FEBS Lett, 2008; 582: 1783-7.

[34] Regazzoni L, Del Vecchio L, Altomare A, et al. Human serum albumin cysteinylation is increased in end stage renal disease patients and reduced by hemodialysis: mass spectrometry studies. Free Radic Res, 2013; 47: 172-80.

[35] Meng X, Lawrenson AS, Berry NG, et al. Abacavir forms novel cross-linking abacavir protein adducts in patients. Chem Res Toxicol, 2014; 27: 524-35.

[36] Meng X, Howarth A, Earnshaw CJ, et al. Detection of drug bioactivation in vivo: mechanism of nevirapine-albumin conjugate formation in patients. Chem Res Toxicol, 2013; 26: 575-83.

[37] Talib J, Beck JL, Ralph SF. A mass spectrometric investigation of the binding of gold antiarthritic agents and the metabolite $[\mathrm{Au}(\mathrm{CN}) 2]$ - to human serum albumin. J Biol Inorg Chem, 2006; 11: 559-70.

[38] Lavergne SN, Whitaker P, Peckham D, Conway S, Park BK, Naisbitt DJ. Drug MetaboliteSpecific Lymphocyte Responses in Sulfamethoxazole Allergic Patients with Cystic Fibrosis. Chemical Research in Toxicology, 2010; 23: 1009-1011.

[39] Sánchez-Gómez FJ, Gayarre J, Avellano MI, Pérez-Sala D. Direct evidence for the covalent modification of glutathione-S-transferase P1-1 by electrophilic prostaglandins: implications for enzyme inactivation and cell survival. Arch Biochem Biophys, 2007; 457: 150-159.

[40] van Iersel ML, Ploemen J-P, Lo Bello M, Federici G, van Bladeren PJ. Interactions of a,bunsaturated aldehydes and ketones with human glutahione S-transferase P1-1. Chem. Biol. Interact., 1997; 108: 67-78.

[41] Sánchez-Gómez FJ, Dorado CG, Ayuso P, Agúndez JAG, Pajares MA, Pérez-Sala D. Modulation of GSTP1-1 oligomerization by inflammatory mediators and reactive drugs. Inflamm Allergy Drug Targets, 2013; 12: 162-171.

[42] Aldini G, Domingues MR, Spickett CM, et al. Protein lipoxidation: detection strategies and challenges. Redox Biol, 2015; 5: 253-266. 
[43] Lacour S, Antonios D, Gautier JC, Pallardy M. Acetaminophen and lipopolysaccharide act in synergy for the production of pro-inflammatory cytokines in murine RAW264.7 macrophages. J Immunotoxicol, 2009; 6: 84-93.

[44] Domingues MR, Domingues P, Melo T, Pérez-Sala D, Reis A, Spickett C. Lipoxidation adducts with peptides and proteins: deleterious modifications or signalling mechanisms? J. Proteomics, 2013; 92: 110-131.

[45] Pichler WJ, Beeler A, Keller M, et al. Pharmacological interaction of drugs with immune receptors: the p-i concept. Allergol Int, 2006; 55: 17-25.

[46] Caron E, Vincent K, Fortier MH, et al. The MHC I immunopeptidome conveys to the cell surface an integrative view of cellular regulation. Mol Syst Biol, 2011; 7: 533.

[47] Norcross MA, Luo S, Lu L, et al. Abacavir induces loading of novel self-peptides into HLAB*57: 01: an autoimmune model for HLA-associated drug hypersensitivity. AIDS, 2012; 26: F21-9.

[48] Bell CC, Faulkner L, Martinsson K, et al. T-cells from HLA-B*57:01+ human subjects are activated with abacavir through two independent pathways and induce cell death by multiple mechanisms. Chem Res Toxicol, 2013; 26: 759-66.

[49] Shetty V, Nickens Z, Testa J, Hafner J, Sinnathamby G, Philip R. Quantitative immunoproteomics analysis reveals novel MHC class I presented peptides in cisplatin-resistant ovarian cancer cells. J Proteomics, 2012; 75: 3270-90.

[50] Yamasaki K, Chuang VT, Maruyama T, Otagiri M. Albumin-drug interaction and its clinical implication. Biochim Biophys Acta, 2013; 1830: 5435-43.

[51] Oakley AJ, Lo Bello M, Nuccetelli M, Mazzetti AP, Parker MW. The ligandin (non-substrate) binding site of human Pi class glutathione transferase is located in the electrophile binding site (H-site). J Mol Biol, 1999; 291: 913-26.

[52] Díez-Dacal B, Sánchez-Gómez FJ, Sánchez-Murcia PA, et al. Molecular interactions and implications of aldose reductase inhibition by PGA $_{1}$ and clinically used prostaglandins. Mol. Pharmacol., 2016; 89: 42-52.

[53] Schoonjans K, Staels B, Auwerx J. The peroxisome proliferator activated receptors (PPARS) and their effects on lipid metabolism and adipocyte differentiation. Biochim Biophys Acta, 1996; 1302: 93-109.

[54] Zorrilla S, Garzón B, Pérez-Sala D. Selective binding of the fluorescent dye 8anilinonaphthalene-1-sulfonic acid to PPARg allows ligand identification and characterization. Anal Biochem, 2010; 399: 84-92.

[55] Thompson RA, Isin EM, Ogese MO, Mettetal JT, Williams DP. Reactive Metabolites: Current and Emerging Risk and Hazard Assessments. Chem Res Toxicol, 2016; 29: 505-33.

[56] Alonso EM, James LP, Zhang S, Squires RH. Acetaminophen Adducts Detected in Serum of Pediatric Patients With Acute Liver Failure. J Pediatr Gastroenterol Nutr, 2015; 61: 102-7.

[57] Heard K, Green JL, Anderson V, Bucher-Bartelson B, Dart RC. Paracetamol (acetaminophen) protein adduct concentrations during therapeutic dosing. Br J Clin Pharmacol, 2016; 81: 562-8.

[58] Delgado M, Garrido F, Pérez-Miguelsanz J, et al. Acute liver injury induces nucleocytoplasmic redistribution of hepatic methionine metabolism enzymes. Antioxid Redox Signal, 2014; In press: $2541-2554$.

[59] Jaeschke H, Williams CD, Ramachandran A, Bajt ML. Acetaminophen hepatotoxicity and repair: the role of sterile inflammation and innate immunity. Liver Int, 2012; 32: 8-20.

[60] Grilo NM, Antunes AM, Caixas U, et al. Monitoring abacavir bioactivation in humans: screening for an aldehyde metabolite. Toxicol Lett, 2013; 219: 59-64.

[61] Dewaele D, Sobott F, Lemiere F. Covalent adducts of melphalan with free amino acids and a model peptide studied by liquid chromatography/tandem mass spectrometry. Rapid Commun Mass Spectrom, 2016; 30: 719-30.

[62] Ariza A, Garzon D, Abánades DR, et al. Protein haptenation by amoxicillin: high resolution mass spectrometry analysis and identification of target proteins in serum. J Proteomics, 2012; 77: 504-520.

[63] Callan HE, Jenkins RE, Maggs JL, et al. Multiple adduction reactions of nitroso sulfamethoxazole with cysteinyl residues of peptides and proteins: implications for hapten formation. Chem Res Toxicol, 2009; 22: 937-48.

[64] Jenkins RE, Kitteringham NR, Goldring CE, et al. Glutathione-S-transferase pi as a model protein for the characterisation of chemically reactive metabolites. Proteomics, 2008; 8: 301-15.

[65] Boerma JS, Dragovic S, Vermeulen NP, Commandeur JN. Mass spectrometric characterization of protein adducts of multiple P450-dependent reactive intermediates of diclofenac to human glutathione-S-transferase P1-1. Chem Res Toxicol, 2012; 25: 2532-41. 
[66] Montanaro S, Lhiaubet-Vallet V, Jimenez MC, Blanca M, Miranda MA. Photonucleophilic addition of the epsilon-amino group of lysine to a triflusal metabolite as a mechanistic key to photoallergy mediated by the parent drug. ChemMedChem, 2009; 4: 1196-202.

[67] Stachulski AV, Meng X. Glucuronides from metabolites to medicines: a survey of the in vivo generation, chemical synthesis and properties of glucuronides. Nat Prod Rep, 2013; 30: 806-48.

[68] Hammond TG, Meng X, Jenkins RE, et al. Mass spectrometric characterization of circulating covalent protein adducts derived from a drug acyl glucuronide metabolite: multiple albumin adductions in diclofenac patients. J Pharmacol Exp Ther, 2014; 350: 387-402.

[69] Yukinaga H, Takami T, Shioyama SH, et al. Identification of cytochrome P450 3A4 modification site with reactive metabolite using linear ion trap-Fourier transform mass spectrometry. Chem Res Toxicol, 2007; 20: 1373-8.

[70] Dietz L, Esser PR, Schmucker SS, et al. Tracking human contact allergens: from mass spectrometric identification of peptide-bound reactive small chemicals to chemical-specific naive human T-cell priming. Toxicol Sci, 2010; 117: 336-47.

[71] Sanderson JP, Naisbitt DJ, Farrell J, et al. Sulfamethoxazole and its metabolite nitroso sulfamethoxazole stimulate dendritic cell costimulatory signaling. J Immunol, 2007; 178: 553342.

[72] Ogese MO, Jenkins RE, Maggs JL, et al. Characterization of Peroxidases Expressed in Human Antigen Presenting Cells and Analysis of the Covalent Binding of Nitroso Sulfamethoxazole to Myeloperoxidase. Chem Res Toxicol, 2015; 28: 144-54.

[73] Yvon M, Wal JM. Identification of lysine residue 199 of human serum albumin as a binding site for benzylpenicilloyl groups. FEBS Lett, 1988; 239: 237-40.

[74] Yvon M, Anglade P, Wal JM. Binding of benzyl penicilloyl to human serum albumin. Evidence for a highly reactive region at the junction of domains 1 and 2 of the albumin molecule. FEBS Lett, 1989; 247: 273-8.

[75] Jenkins RE, Meng X, Elliott VL, Kitteringham NR, Pirmohamed M, Park BK. Characterisation of flucloxacillin and 5-hydroxymethyl flucloxacillin haptenated HSA in vitro and in vivo. Proteomics Clin Appl, 2009; 3: 720-9.

[76] Jenkins RE, Yaseen FS, Monshi MM, et al. beta-Lactam antibiotics form distinct haptenic structures on albumin and activate drug-specific T-lymphocyte responses in multiallergic patients with cystic fibrosis. Chem Res Toxicol, 2013; 26: 963-75.

[77] Whitaker P, Meng X, Lavergne SN, et al. Mass spectrometric characterization of circulating and functional antigens derived from piperacillin in patients with cystic fibrosis. J Immunol, 2011; 187: 200-11.

[78] Magi B, Marzocchi B, Bini L, Cellesi C, Rossolini A, Pallini V. Two-dimensional electrophoresis of human serum proteins modified by ampicillin during therapeutic treatment. Electrophoresis, 1995; 16: 1190-2.

[79] Mayorga C, Obispo T, Jimeno L, et al. Epitope mapping of beta-lactam antibiotics with the use of monoclonal antibodies. Toxicology, 1995; 97: 225-34.

[80] Fujiwara K, Shin M, Miyazaki T, Maruta Y. Immunocytochemistry for amoxicillin and its use for studying uptake of the drug in the intestine, liver, and kidney of rats. Antimicrob Agents Chemother, 2011; 55: 62-71.

[81] Carey MA, van Pelt FNAM. Immunochemical detection of flucloxacillin adduct formation in livers of treated rats. Toxicology, 2005; 216: 41-48.

[82] Garzon D, Ariza A, Regazzoni L, et al. Mass spectrometric strategies for the identification and characterization of Human Serum Albumin covalently adducted by Amoxicillin: ex vivo studies. Chem Res Toxicol, 2014; 27: 1566-1574.

[83] Cernuda-Morollón E, Pineda-Molina E, Cañada FJ, Pérez-Sala D. 15-Deoxy- $\Delta^{12,14}$-prostaglandin $\mathrm{J}_{2}$ inhibition of NF- $\mathrm{KB}$ DNA binding through covalent modification of the p50 subunit. J. Biol. Chem., 2001; 276: 35530-35536.

[84] Garzón B, Gayarre J, Gharbi S, et al. A biotinylated analog of the anti-proliferative prostaglandin $\mathrm{A}_{1}$ allows assessment of PPAR-independent effects and identification of novel cellular targets for covalent modification. Chem Biol Interact, 2010; 183: 212-221.

[85] Sánchez-Gómez FJ, González-Morena JM, Vida Y, et al. Amoxicillin haptenates intracellular proteins that can be transported in exosomes to target cells. Allergy, 2016; In press. Doi: 10.1111/all.12958.

[86] Li XB, Zhang ZR, Schluesener HJ, Xu SQ. Role of exosomes in immune regulation. J Cell Mol Med, 2006; 10: 364-75.

[87] McCoy-Simandle K, Hanna SJ, Cox D. Exosomes and nanotubes: Control of immune cell communication. Int J Biochem Cell Biol, 2016; 71: 44-54. 


\section{Figure Legends}

Figure 1. Flow diagram of the approach to identify protein targets for modification by biotinylated amoxicillin. Briefly, cells are incubated in the presence of biotinylated amoxicillin, cells and conditioned medium are collected and analyzed by 2D-electrophoresis in duplicate gels. One gel is stained for total protein and its duplicate is transferred to nylon membranes and the blot incubated with horseradishperoxidase for detection of proteins bearing a biotin signal. Spots positive for biotin in the blot are matched to the protein spots in the gel, which are excised and analyzed by peptide fingerprinting.

Figure 2. Competition or cooperation between protein modifications by drugs and electrophilic mediators or oxidants. Similarly to what has been described for endogenous electrophilic mediators, modification of proteins by drugs could have diverse consequences, of which several examples are presented. 1) If modification leads to protein unfolding, this can expose additional sites for modification in the protein. 2) Protein oxidation can increase or decrease its reactivity towards drugs. For instance, cysteine oxidation to sulfenic acid has been proposed to favor protein modification by sulfamethoxazole. 3) For some proteins, like GSTP1-1, there may be competition for among several modifications for the same residue. For instance, Cys47 has been shown to be modified by electrophilic prostaglandins, ethacrynic acid and chlorambucil, and a competition between these agents can be evidence in vitro. 4) Protein modification by oxidation can induce conformational alterations shielding reactive residues. See the text for a more detailed explanation.

Figure 3. Formation of protein adducts with different drugs or their metabolites through covalent binding

Figure 4. Potential role of drug-bearing exosomes in the intercellular transfer of haptenated proteins. In addition to classical pathways in which haptenated serum proteins can be taken up and processed by cells, we have observed that proteins can be haptenated intracellularly and be secreted either as soluble proteins or in extracellular vesicles. These vesicles can be taken up by other cells and therefore can constitute an additional vehicle for haptenated proteins. In addition, proteins already present in circulating exosomes from several cells could be haptenated, thus expanding the array of structures potentially involved in hypersensitivity responses. 
Table 1. Some of the drug-adducts described. The residues modified are shown as well as whether they have been formed in patients $\left({ }^{a}\right)$ or under in vitro conditions $\left({ }^{b}\right)$. References correspond to: Meng, 2014 [35]; Ariza, 2012 [62]; Hammond, 2014 [68]; Jenkins, 2009 [75]; Meng, 2013 [36]; Whitaker, 2011 [77].

\begin{tabular}{|c|c|c|c|}
\hline Drug & Target Protein & Residues Modified & Reference \\
\hline Abacavir & HSA & $\begin{array}{l}\text { Lys } 159^{\mathrm{b}}, \text { Lys } 190^{\mathrm{b}}, \\
\text { His146, }{ }^{\mathrm{a}, \mathrm{b}}, \text { Cys34 } \\
\text { a, b }\end{array}$ & Meng, 2014 \\
\hline Amoxicillin & HSA & $\operatorname{Lys}_{190}{ }^{\mathrm{a}}$, Lys195 & Ariza, 2012 \\
\hline Diclofenac & HSA & Lys195 $^{\mathrm{a}, \mathrm{b}}$, Lys199 $9^{\mathrm{a}, \mathrm{b}}$ & $\begin{array}{c}\text { Hammond, } \\
2014\end{array}$ \\
\hline Flucloxacillin & HSA & Lys $190^{\mathrm{a}, \mathrm{b}}$, Lys $212^{\mathrm{a}, \mathrm{b}}$ & Jenkins, 2009 \\
\hline Nevirapine & HSA & $\begin{array}{c}{\text { His } 146^{\mathrm{a}, \mathrm{b}}, \text { His } 242^{\mathrm{b}}}, \\
\text { His } 338^{\mathrm{b}}, \text { Cys } 34^{\mathrm{b}}\end{array}$ & Meng, 2013 \\
\hline Piperacillin & HSA & 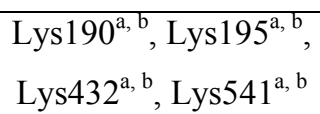 & Whitaker, 2011 \\
\hline
\end{tabular}



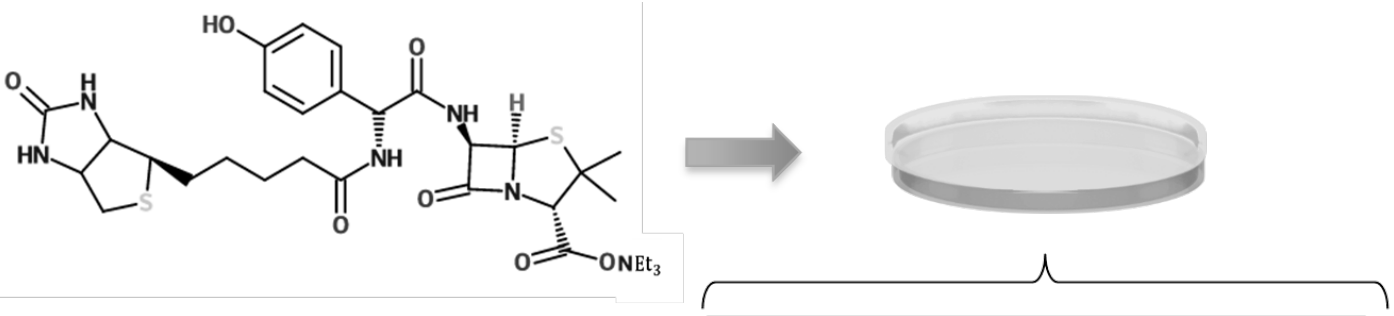

Biotinylated amoxicillin

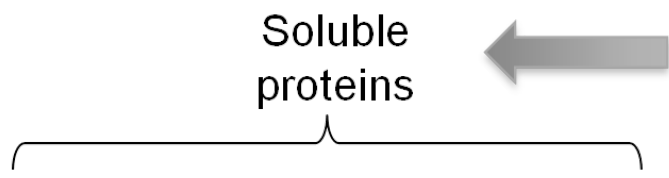

Conditioned medium

2D Electrophoresis

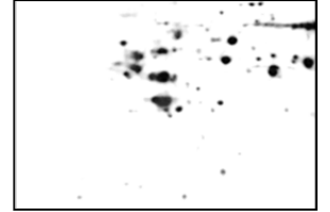

HRP-Streptavidin

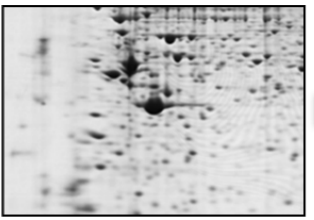

Total protein
- Band excision

- Digestion

- MS

- Identification

\section{Validation}

- In vitro studies

- Immunoprecipitation

- Immunoblotting 


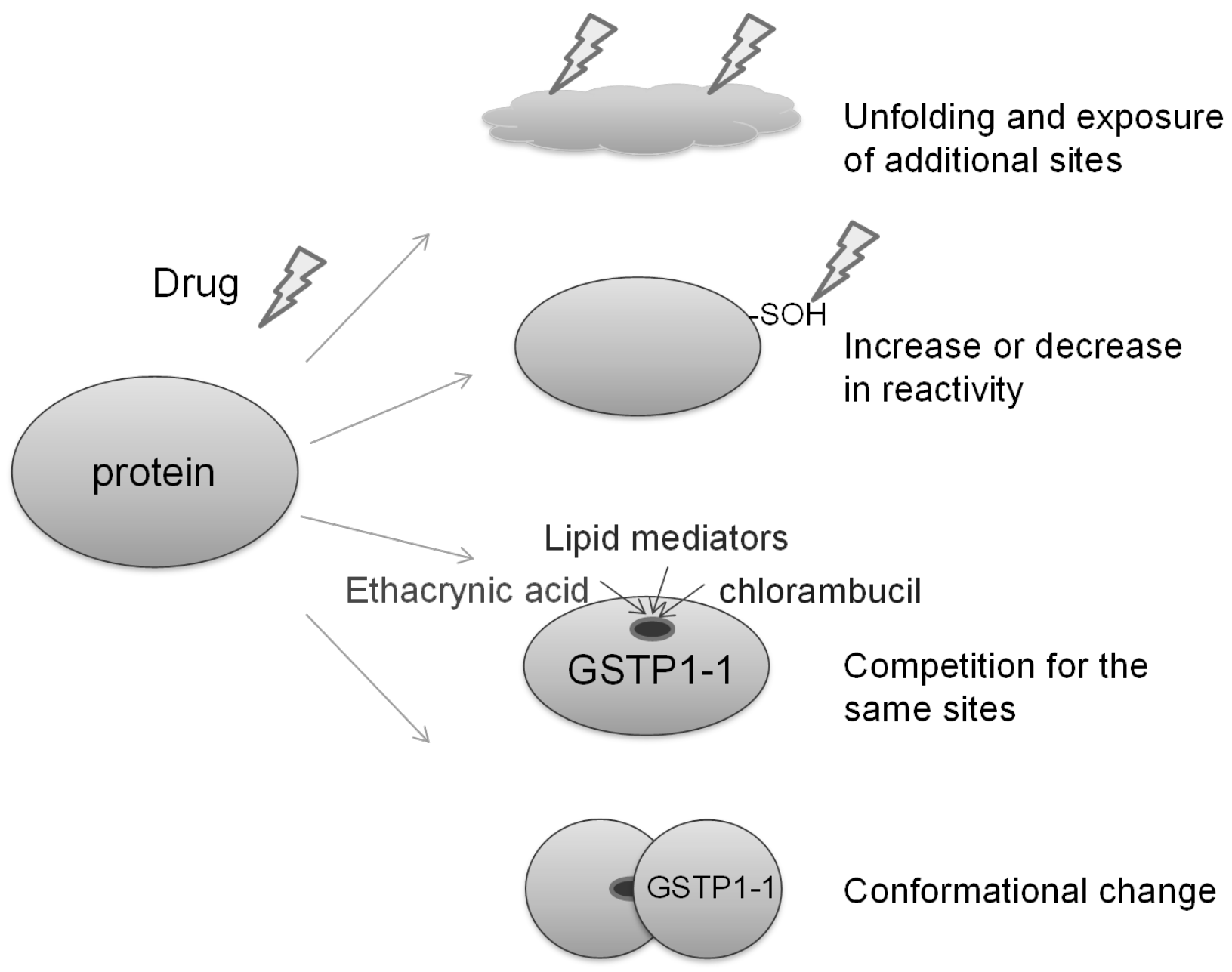



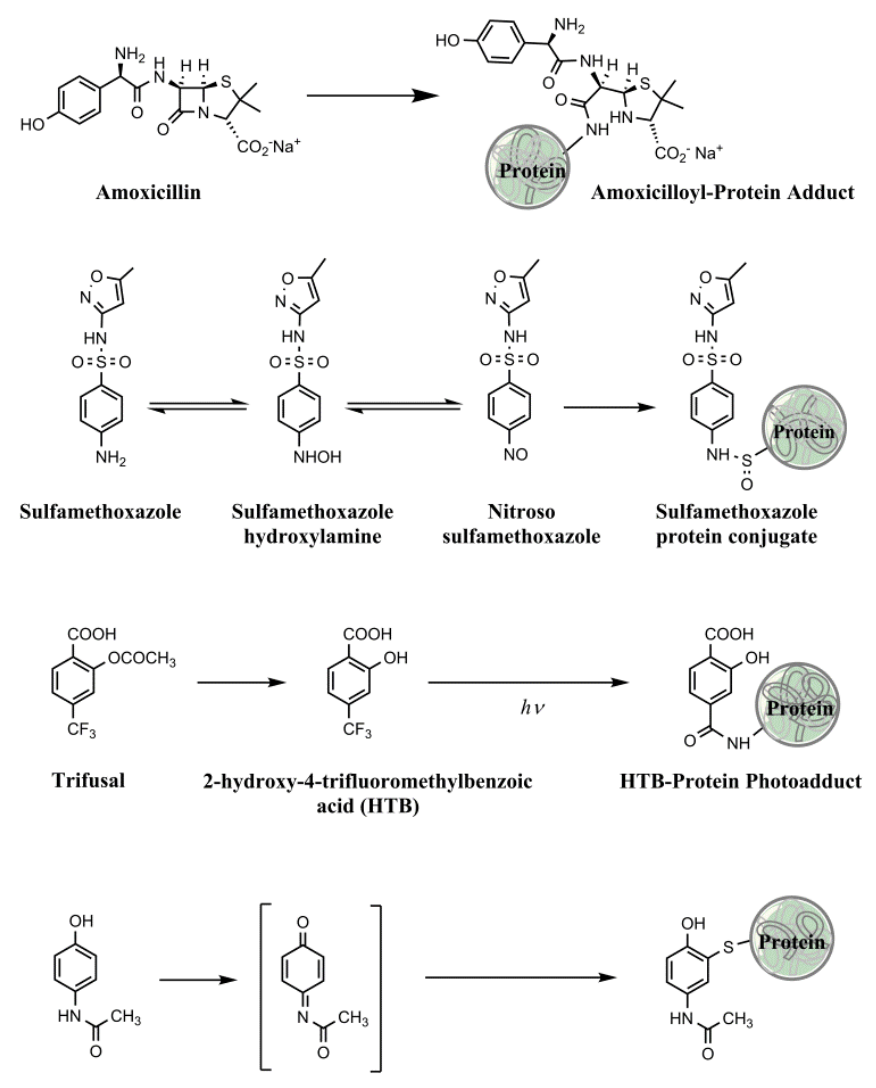

Paracetamol N-acetyl-p-benzoquinoneimine (NAPQI)

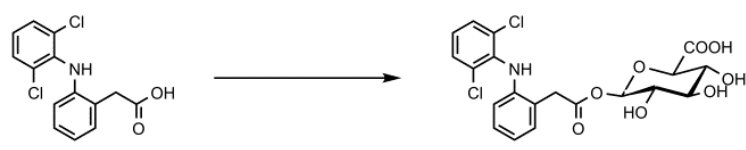

Diclofenac-acyl-glucuronide
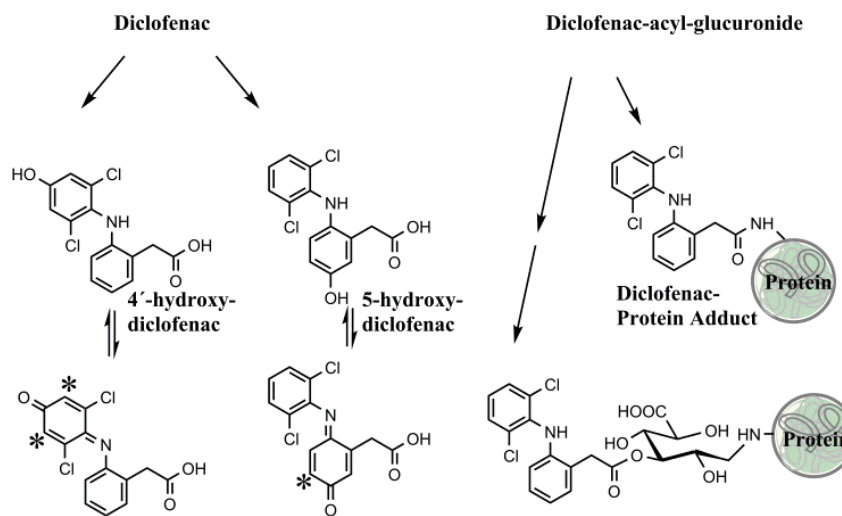

4'-hydroxy-diclofenac quinoneimine

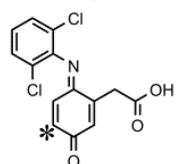

4'-hydroxy-diclofenac quinoneimine
Formation of adducts through reaction with thiols at $C^{*}$

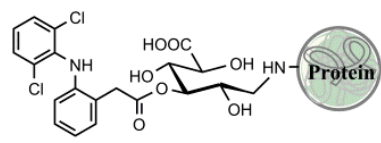

Diclofenac-acyl-glucuronideProtein Adduct

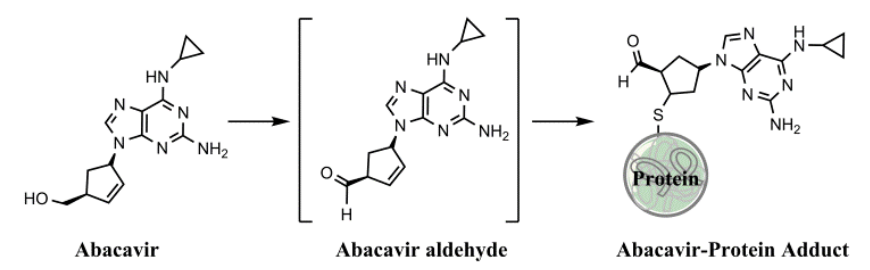

Fig. 3 


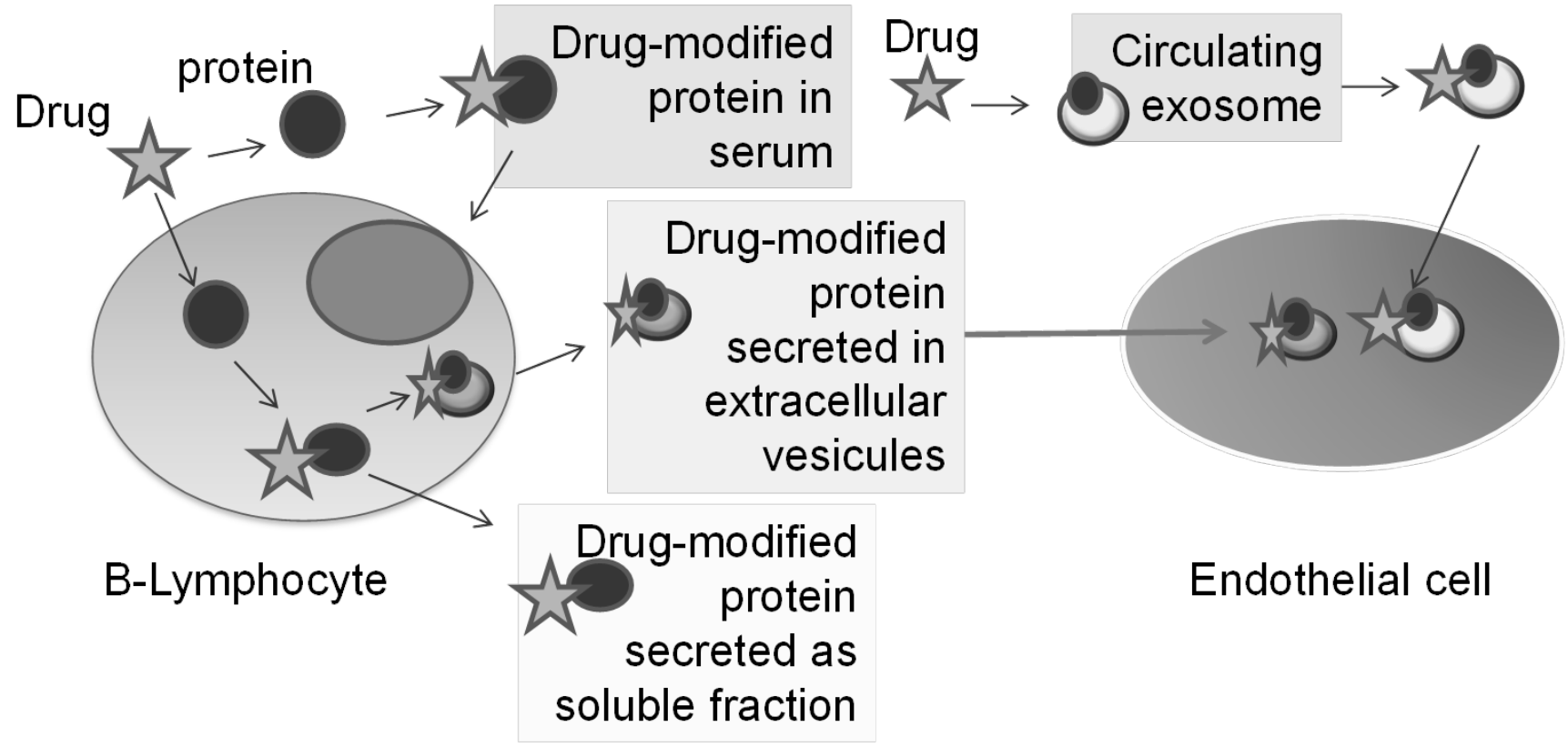

